\title{
It takes a network to defeat a network: What Collective Action practitioners can learn from research into corrupt networks
}

Claudia Baez Camargo, Head of Public Governance Jacopo Costa, Senior Research Fellow

Vanessa Hans, Private Sector Specialist Lucy Koechlin, Senior Lecturer at the Institute of Social Anthropology, University of Basel

Scarlet Wannenwetsch, Project Associate Anti-Corruption Collective Action

\section{Key takeaways}

$\rightarrow$ Research in Tanzania and Uganda has illuminated how informal networks link private and public sector actors to pursue common illicit goals, such as gaining an unfair business advantage or decreasing taxes owed. Held together by corruption, the networks are highly resilient and effective.

$\rightarrow$ Collective Action initiatives also typically create networks of private and public sector actors, but the goals here are positive and transparent. They may include raising standards of integrity and fair business in a specific industry sector or geographical area.

$\rightarrow$ Understanding how corrupt networks function and the problems they solve for the actors involved - could help Collective Action practitioners increase the effectiveness and resilience of their initiatives.

$\rightarrow$ A key lesson is that anti-corruption initiatives that focus on solving problems for stakeholders, especially business-critical problems, offer more powerful incentives to engage. Initiatives focused solely on promoting compliance and integrity for their own sake may be less attractive. $\rightarrow$ Where business people resort to corruption because they feel they have no other choice, Collective Action initiatives have the potential to offer a transparent, non-corrupt alternative. To do this effectively, they need to recruit strategically. Just as corrupt networks are reliant upon having the right people with the right powers in the right places, so Collective Action initiatives need members with particular characteristics, skills and functions.

$\rightarrow$ For informal networks, personal connections are essential - even if they have to be cemented by bribes and favours. Collective Action initiatives also need to work hard to build trust between members, while maintaining credibility and independence.

$\rightarrow$ To break up collusive networks of corrupt public and private sector actors, it is important to have effective reporting or whistleblowing mechanisms. As well as supporting law enforcement in detecting and investigating corruption, the existence of a credible reporting mechanism can mobilise business actors to engage in efforts to prevent corruption. The High Level Reporting Mechanism is one such approach. 


\section{Key takeaways (continued)}

$\rightarrow$ Anti-corruption initiatives that focus purely on adding formal controls to high-risk processes, like audits and sanctions, can backfire. This is because they add complexity while not addressing the informal mechanisms underlying the corrupt acts. Initiatives that include monitoring project implementation and outcomes, such as whether construction contracts are actually being carried out, could be more effective than a strict compliance and control-based approach alone.

$\rightarrow$ Though informal networks can be resilient and effective, there may well be windows of opportunity to break them up. Examples include if a new government comes to power on an anti-corruption ticket or where there is strong pressure from citizens to increase transparency and accountability. Seize them!

\section{Background}

This Policy Brief distils recommendations for Collective Action practitioners based on empirical insights on certain forms of corruption involving private-sector actors.

Field research carried out in Tanzania and Uganda produced detailed case studies that show how informal networks link private and public sector actors to pursue common illicit goals (Baez Camargo et al, 2021), such as gaining an unfair business advantage, avoiding a sanction, decreasing taxes owed or jumping the queue at the point of delivery of public services. Corruption, most often bribery, is the currency that works to cement and nurture those networks. This Policy Brief is based on that research and a series of in-depth interviews with Collective Action practitioners working in Africa, Eastern Europe and Latin America.

The goal of this Policy Brief is to extract insights from what we have learned about the networks that fuel corruption, which are purposeful and resilient, and discuss implications for anti-corruption Collective Action initiatives (CAls). We believe CAls, as diverse as they may be, share a network-building logic: they are in effect networks of different stakeholders committed to working together to tackle corruption. Because of this, it is logical to consider CAls as a type of network intervention (Valente, 2012).

\section{Further reading}

For those unfamiliar with the latest research on corruption and informal networks, we recommend you read our 2021 GI-ACE report on Informal networks as investment in East Africa and related case studies (Baez Camargo et al, 2021). For more on anti-corruption Collective Action, see the B20 Collective Action Hub resource centre at: collective-action.com. 


\section{Why do business people resort to corruption?}

Informal networks are useful to obtain business opportunities with the public sector and to allow business to run smoothly. From the perspective of the business people who join these networks, corruption is not a goal in and of itself. Rather, corruption is the means to circumvent formal controls and compliance checks in the mechanisms governing public procurements and other processes in the public administration. The goal is to win business opportunities and contracts, and/ or to facilitate the processing of business permits, tax clearances, licences and other services, which are time-consuming and sometimes made even more complicated by abusive public officials.

Crucially, corruption is also the means to establish and nurture connections with the right people, such as those public officials who can expedite a permit or those in charge of handling public procurement processes. When a bribe is exchanged, it represents not just a one-off transaction, but builds a social connection. Bribery becomes an ongoing mechanism to maintain the right social connections and to keep the informal networks functional.

\section{What does the research show about how corrupt networks function?}

Informal networks help balance the supply and the demand for corruption.

\section{SEEKERS}

On the demand side are citizens and business people who wish to obtain services in a timely manner, or who wish to do business with public entities. These are people who want to obtain an informal service, resource or advantage that would not be attainable by following formal rules and procedures. We have labelled them as "seekers".
The evidence from Tanzania and Uganda shows that business people often offer facilitation payments to expedite services and the processing of licences and permits because without the help of an informal network of public officials, obtaining the required documentation and services to run a business is perceived to be difficult and time-consuming.

The research also reveals business people resorting to bribing and giving kickbacks to public officials to win contracts and business opportunities. This appears to be because they share the perception that without an informal connection they will never succeed, no matter whether their firms follow all the formal rules and meet technical specifications in tenders. Without an informal connection with the right people, there is no contract. And without bribes, the social connection needed to obtain that contract is not strong enough.

Informal networks are effective because they help to address problems or challenges that the formal systems do not. The research suggests that very often business people join these informal networks because they feel that they have no choice, or that the alternatives (long waiting times and troubles) are costlier than paying the bribes that are required to activate an informal network that will provide an expedited solution.

\section{BROKERS}

In this configuration, a key category of actors are the

brokers, whose role is to link up demand and supply, negotiating access to the doers on behalf of the seekers. Brokers live off their contacts with the networks of corrupt officials, which they must lubricate regularly through a predictable exchange of bribes to keep the trust of the doers.

\section{DOERS}

On the supply side are networks of public officials, insiders to the public institutions, who have the ability to "make things happen". This means, for example, manipulating formal procedures and granting favours, or making life difficult for users and contractors who are outside the network and/or do not pay a bribe. We have labelled these individuals as "doers". 
The division of labour tends to become more complex as the size of the network increases or when the bureaucratic processes involved in reaching the goals are particularly complex to override. For example, other roles in the networks include:

- Facilitators: individuals who are tasked to follow the file or case of the seeker throughout long bureaucratic procedures to ensure it gets prioritised.

- Intermediaries: individuals who negotiate the terms of the exchange on behalf of the networks of doers and who receive bribes and deliver the "goods" (business licence, land deed, etc). The intermediaries protect the networks of insiders from detection, providing a buffer between the seekers and their brokers on the one side and the doers on the other side.

- Instigators: are those who mastermind the informal schemes and play for the most part a coordinating role.

For the informal networks to properly function, different actors are responsible for undertaking different tasks. There are key individuals who, because of their formal powers and abilities or because of their informal connections, must be co-opted into the network in order to be able to achieve the desired goals.

We distinguish two types of networks based on the nature of the engagement between seekers and doers:

- Some networks are extortive. This is the case, for example, when public officials slow down or even halt bureaucratic processes for users who refuse to give bribes. In other cases, business people report feeling compelled to give in to the demands of corrupt procurement officials because they believe otherwise they will never get any business opportunities with the public entity in question.

- Other networks are collusive. This is the case, for example, when business people and public officials conspire to defraud formal tendering mechanisms, or when bribes are exchanged in order to avoid a sanction or obtain an undue benefit.

\section{What are the lessons for anti-corruption practitioners? \\ Anti-corruption initiatives should focus on problem solving as an incentive for stake- holders to engage}

The case studies show that informal networks held together by corruption are effective and valued because they solve problems - often basic problems like how to get a business licence or register land. This suggests that reforms focusing on goals such as improving the ease of doing business and getting rid of the red tape could go a long way in addressing the demand side of corruption.

This could be a fruitful approach for several reasons. Experience shows that Collective Action initiatives that focus purely on promoting integrity and compliance for their own sake - rather than thinking about how the initiative can solve problems for members or enable them to access something that will help their business - tend to fail.

This is firstly because initiatives that focus solely on building integrity tend to attract those businesses that are already clean.

Furthermore, approaches predicated solely on building integrity tend to impose a triple burden on small and medium-sized enterprises (SMEs):

1. implementing compliance reforms is costly to begin with;

2. the benefits from abstaining from informal solutions are uncertain and will only materialise in some unspecified future; and

3. the costs of being sidelined by corrupt public officials and losing out to competitors that continue to rely on corruption are immediate.

There is therefore an intertemporal dilemma that works against the incentives to adopt a purely integrity-based approach. 


\section{Box 1: Why did so many companies sign up for Nigeria's Corporate Governance Rating System?}

An example of a CAI that achieved success by helping members gain access to a sought-after asset in return for adopting strong compliance controls is the Corporate Governance Rating System (CGRS) developed jointly by the Business Action Against Corruption project (BAAC) of the Convention on Business Integrity ( $\mathrm{CBi}$ ) and the Nigerian Stock Exchange (NSE).

Conceived in the aftermath of the global financial crisis on the Nigerian stock exchange, the CGRS rewards businesses that have adopted a stringent set of compliance standards with a place on the NSE's Premium Board, which is the listing segment for the elite group of issuers that meet the Nigerian Exchange's most stringent corporate governance and listing standards. This rating mechanism addresses the needs of companies wishing to raise capital by signalling that they comply with international standards. Key business players in Nigeria, representing $80 \%$ of market capitalisation, have since joined this initiative. This demonstrates that finding the right incentives and solving problems (how to raise capital on international markets) can encourage many more companies to engage initiatives to improve their integrity and compliance - not just those who are already interested in anti-corruption.

This pragmatic approach holds the potential of achieving a more substantive long-term impact, because it offers rewards that are sought after and therefore attracts important business actors. This in turn has triggered a demonstration effect, with many companies joining the initiative following the example of certain trendsetters.

\section{Set up and recruit strategically for the CAI - people are the key to its success}

There are many instances in which business people are subjected to requests for bribes and give in because they feel they have no choice but to do so. In those cases, business actors suffer from the costs that corruption generates for them and therefore have a strong interest to act against it.

CAls can address the demand side of corruption by providing these actors with transparent, non-corrupt alternatives.

However, bringing together the victims of corruption in a CAI may not be enough. In order to develop functional alternatives to the informal networks, CAls need to recruit the right actors that can deliver results for victims of corruption who are otherwise unable to resist corruption on their own. Just as the networks of corruption rely on individuals who can carry out particular tasks conducive to achieving the goals of the network, so CAls should co-opt stakeholders strategically.

What does this look like in practice?

First, a CAI needs the equivalent of the instigators we identified earlier - those who mastermind the informal schemes and play a coordinating role. In the context of a CAI, these are the key individuals, groups or entities that identify the need for a Collective Action solution, mobilise resources and throw their institutional weight behind the initiative. Instigators might be, for example, multi-stakeholder groupings that bring together representatives of different key constituencies which are needed to ensure the CAl can deliver on its promises. These can be a mix of international, public, private and civil society actors, such as the Consensus Frameworks in the Healthcare industry in APEC.

Connecting the private-sector actors (seekers) with those who can provide non-corrupt solutions to address business needs (the equivalent of the "doers" in the informal networks) might necessitate a "broker" with convening power and credibility. Experience from a broad range of Collective Action practitioners indeed 
suggests that a dedicated function is needed to maintain communication flows, plan and chair regular engagement and dialogue, and promote trust-building interactions. This brokerage function is not only key during the initial stages, when CAls need to establish a basis of mutual trust and sense of collective interest, but also to ensure that the parties remain committed and the network functional. International organisations can play such a broker role, especially when trust amongst local private- and public-sector actors is low. Again similarly to the informal networks, it may be necessary for CAls to recruit strategically for certain skills. Legal and other types of experts might be crucial to play a "facilitator" role to solve arising issues depending on the area or sector being addressed by the CAI. "Intermediaries" might also play a central role in CAls that involve whistleblower mechanisms, where the anonymity and safety of those blowing the whistle is enhanced by bringing on board a neutral, credible party.

\section{Box 2: How the setup and staffing of the Business Ombudsman Council of Ukraine contribute to its success}

An excellent example of an initiative that has been strategic in terms of its setup and staffing is the Business Ombudsman Council (BOC) of Ukraine. The $\mathrm{BOC}$ is a multi-stakeholder alternative dispute resolution (ADR) mechanism aimed at protecting business against abuse and breach of authority. It fills an institutional gap caused by mistrust vis-à-vis conventional dispute resolution mechanisms. The BOC, as an institution, is a broker of sorts that provides pre-trial dispute resolution services by interchangeably employing evaluative and facilitative mediation techniques to address malpractices specified in complaints lodged by businesses against all types of public authorities, including law enforcement agencies and bodies of sub-national governance.

The BOC has a Supervisory Board which brings together the main business associations in Ukraine, the Government of Ukraine and two international organisations (OECD and EBRD). Such an inclusive configuration gives credibility to the $\mathrm{BOC}$ and guarantees its independence and impartiality. The BOC's independence is also reinforced by a multi-donor financing mechanism managed by the EBRD and funded by the EU and more than a dozen countries.

Furthermore, the BOC is staffed by highly qualified professionals with practical experience in law, strategic management, economics, auditing, and risk management including two Deputy Business Ombudsman.

Finally, each incumbent Business Ombudsman of Ukraine (who also supervises the work of four investigators) is a person of great international standing and reputation, who confers further reputational leverage, authority and credibility to the BOC.

The high rate at which the Government adopts the BOC's recommendations issued in connection with the investigation of individual cases (around $87 \%$ ) is impressive, especially given that the BOC, by definition, is not vested with any binding authority. This success rate is testimony to the fact that proper use of expertise, meritocratic staffing, independence and credibility could be very effective while designing institutional mechanisms that businesses can rely on to solve problems with the public sector. 


\section{Invest in building trust to develop a strong network over time}

Evidence from the research into corrupt networks indicates that trust-building among network members is a key prerequisite. Trust can be built through the predictability and reliability with which transactions and exchanges take place among the network participants, often cemented in the form of the exchange of bribes. Concretely, the research evidence suggests trust is built through a process of "tit-for-tat" exchanges, where also failing to do good on a payment or delivering a promised service or resources results in some form of control mechanism, which can include being expelled from the network and therefore of the benefits it confers. Corrupt networks, furthermore, do not only function to address momentary issues but can also be activated when new issues or opportunities arise for the group. But to do so, the network needs to be continuously nurtured and maintained.

The lesson about building and cementing relationships that transcend the immediate needs is transferrable for CAls, especially those operating in contexts of systemic corruption. To be effective as an alternative to the corrupt network, CAls need to establish themselves as a first port of call, where members of the network turn to discuss problems and come up with effective ways to address them. This requires a certain level of continuity and ongoing demonstration of business benefits to build trust. The importance of building trust also points to the need for sustained engagement in CAls. It reinforces the point made above about focusing on delivering benefits or addressing challenges, and going beyond a purely integrity-focused approach.

A good example of a CAl that has cultivated and built trust is the Maritime Anti-Corruption Network. Among a range of activities and tools, it has developed a mechanism for captains and other maritime actors to anonymously report issues they face in ports. This has developed into one of the most trusted and utilised reporting mechanisms in the Collective Action field.

\section{Enhance both detection and prevention through effective whistleblowing or reporting mechanisms}

Some networks of corruption are collusive, which means they represent a special challenge to anticorruption practitioners because none of those involved have an incentive to abandon the status quo. Collusive networks are often behind grand corruption schemes that deprive the public of millions of dollars' worth of investment, as illustrated in a recent Working Paper analysing the corrupt network linking disgraced former Peruvian President Alejandro Toledo and the Odebrecht construction company at the heart of the Lava Jato scandal (Costa, 2021).

In dealing with collusive networks, a law enforcement response is crucial, including a strong investigative and detection capability. Experience shows that investing in credible whistleblowing and corruption reporting mechanisms can not only support detection and investigation, but also effectively mobilise business actors exposed to the fraudulent activities of the collusive networks.

Reporting mechanisms don't have to be purely linked to law enforcement. CAl practitioners have highlighted the importance of active corruption prevention work at the wider government level, which is much better positioned to build relationships and constructively engage with the private sector than traditional law enforcement agencies. Textbox \#3 shows an example of a Collective Action approach that operationalises an effective reporting channel for high-risk public procurement processes. 


\section{Box 3: The High Level Reporting Mechanism: a reporting mechanism that builds trust and de-escalates corruption issues}

The High-Level Reporting Mechanism (HLRM) is a prime example of a collectively developed reporting tool designed to prevent corruption and anti-competitive behaviour in the public tendering process. The HLRM enables stakeholders to raise alerts of potential bribery or unfair business practices through secure, easily accessible channels, which are subsequently communicated to a designated independent panel of experts.

Following their analysis of the alert, taking into consideration all necessary information, the panel works to provide a transparent resolution through open discussion and mediation with all relevant actors. The aim is to resolve the issue with minimal loss of time and money and allow the project to continue smoothly.

The mechanism is designed to be tailored to each country's context and is developed in collaboration with representatives of the public sector, business and civil society. This approach ensures it meets the needs of all stakeholders involved, thus increasing buy-in as well as ownership of the mechanism.

In the research in Uganda and Tanzania, business people explained that they had no choice but to acquiesce to joining corruption networks as the only means to have a chance at winning public tenders. Experiences from countries that have implemented a HLRM, such as Argentina and Colombia, illustrate how credible reporting channels work to make business processes both more effective and cleaner.

\section{Focus on outputs and outcomes, not just on tick-box compliance}

It is commonly assumed that to control corruption, you have to implement more controls in the form of law enforcement, audits and sanctions. However, one of the lessons learned from how corrupt networks work is that, paradoxically, in highly informal contexts, more formal controls may breed more corruption. This is partly because more people may need to be bribed to achieve the desired outcomes.

More than an insurmountable obstacle, formal controls and the actors who are supposed to uphold them (such as law enforcement officers or auditors), become the targets of the co-optation strategies deployed by individuals participating in the informal networks. One of the case studies from Tanzania shows that adding more controls in a public licensing process simply adds another layer of complexity over the existing red tape. It makes no difference to the outcome, because the red tape and extra controls are all simply overridden by social connections and bribery (See Figure 1).

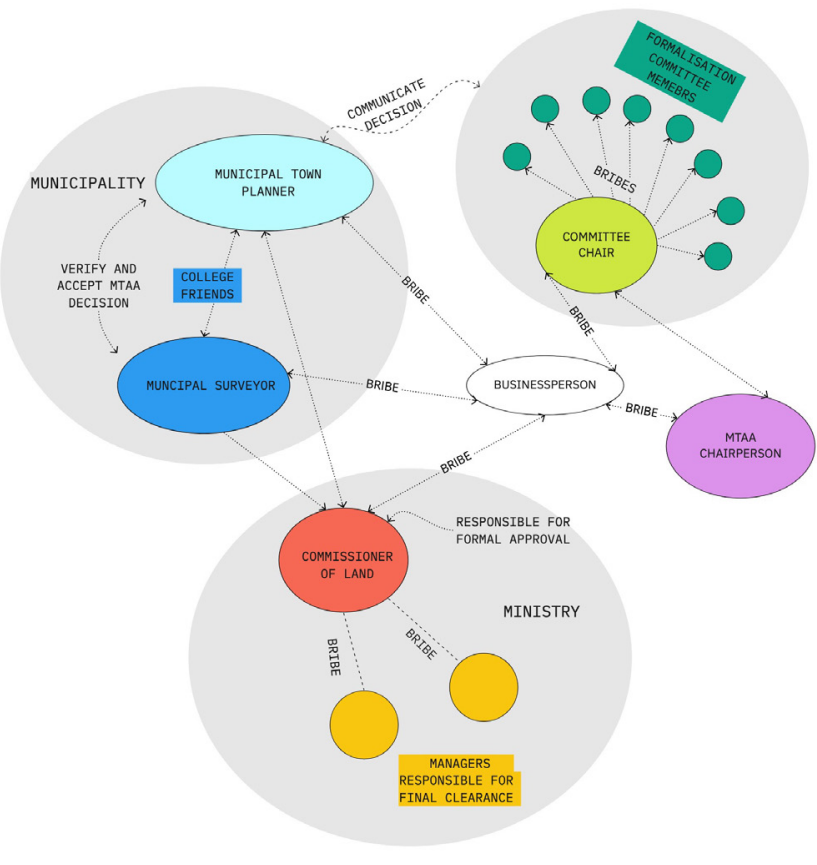

Figure 1

Collusive network to win a competitive land formalisation process in Tanzania 
In order to tackle collusive networks that are able to override internal controls, a multi-pronged approach might be necessary. CAls that support corruption reporting mechanisms (such as the HLRM - see textbox 3) can be fruitfully paired with civil society and community-based stakeholders who monitor the execution of strategic public contracts through social audits or similar activities.

Transparency initiatives in procurement, such as the CoST Infrastructure Transparency Initiative, are becoming increasingly popular. Though immensely valuable, they will not yield the expected results unless there are stakeholders trained and ready to scrutinise the information. Social audits can empower civil society actors to uncover the use of substandard materials and other types of fraud during contract implementation. Making monitoring and effective reporting mechanisms available at the different stages of the procurement and contract execution chain can greatly help reduce opportunities for corruption.

By doing so, at least part of the emphasis is shifted from a purely compliance-based approach to an outputs and outcomes-based approach that can detect the footprints of corruption in the form of substandard inputs, incomplete projects and unsubstantiated cost increases.

\section{Harness windows of opportunity to break down informal corrupt networks and launch CAls}

The informal networks associated with corruption are effective and resilient, but not invincible. In past research conducted by the Basel Institute, we have also identified several triggers linked to network collapse. Electoral defeat, mass demonstrations, and disintegration when a network becomes too big and complex to manage are among the reasons why informal networks may be seriously destabilised.

Two of the examples mentioned above of successful CAls (the CGRS and the BOC) were conceived in the wake of some type of upheaval (the Nigerian stock exchange crash and the Ukraine Maidan Revolution). In these situations, the existing informal networks were disrupted and allowed these new CAI networks to step in.

\section{Putting it into practice}

- A value-based approach might not be enough to incentivise stakeholders to engage in an anti-corruption CAI. As with the informal networks, successful initiatives help address concrete challenges that matter to business. Pragmatism beats idealism and values. The introduced measures should be functional to the interests of business players and find an alignment with the broader anti-corruption goals.

- Consider not just direct but also indirect pathways to promote the fight against corruption. Improving the broader business environment, for example through measures to cut red tape, can be as important as directly implementing specific anti-corruption measures or acts that put a heavy burden on the business players.

- As with the informal networks, CAls need to recruit strategically. Who are the critical actors and what functions will they need to perform for the CAl to succeed? Where are they and what kind of incentives (material, relational, logistic) can they be offered to become involved in an initiative?

- For informal networks, personal connections are essential. CAls also need to work hard to build trust between members, while maintaining credibility and independence.

- Paying attention to actual outputs and outcomes, especially in infrastructure projects where the results can be seen on the ground, can usefully complement a compliance-based approach to anti-corruption.

- Consider harnessing windows of opportunity to break down informal corrupt networks and launch CAls, for example following the election of a new government on a strong anti-corruption ticket. 


\section{Keywords}

\section{informal networks}

private-sector corruption

anti-corruption evidence

multi-stakeholder partnerships

Collective Action initiatives

\section{About this Policy Brief}

This publication is part of the Basel Institute on Governance Policy Brief series, ISSN 2624-9669. It is licensed under a Creative Commons Attribution-NonCommercial-NoDerivatives 4.0 International License (CC BY-NC-ND 4.0).

Suggested citation: Baez Camargo, C., Costa, Hans,V., J., Koechlin, L. and Wannenwetsch, S. (2021) It takes a network to defeat a network: What Collective Action practitioners can learn from research into corrupt networks. Policy Brief 8, Basel Institute on Governance.

The research underpinning this Policy Brief was funded by the Global Integrity Anti-Corruption Evidence Programme, funded with UK Aid from the British people.

ACE $\frac{\text { Anti-Corruption Evidence }}{\text { Research Programme }}$ 